\title{
Effects of air pollution and meteorological parameters on human health in the city of Athens, Greece
}

\author{
Emmanouil Mentzakis $^{*, a}$ and Doriana Delfino ${ }^{\mathrm{b}}$ \\ ${ }^{\text {a }}$ Health Economics Research Unit, University of Aberdeen, AB25 2ZD, Scotland, UK \\ ${ }^{\mathrm{b}}$ Environment Department, University of York, YO10 5DD, England, UK
}

\begin{abstract}
The aim of this study is to quantify the impacts of air pollution and meteorological parameters on human morbidity and to test whether different model specifications and approaches yield different results. Generalised additive and linear models along with monthly time series data for $\mathrm{CO}, \mathrm{NO}, \mathrm{NO}_{2}, \mathrm{SO}_{2}, \mathrm{O}_{3}$, average/maximum/minimum air temperature, relative humidity and atmospheric pressure are employed in order to investigate their association with three indicators of morbidity (circulatory diseases, respiratory diseases and skin diseases) in the city of Athens, Greece, for the period January 1987 - December 1999. Our results indicate that an exacerbation in pollution levels of $\mathrm{SO}_{2}$ significantly increase the number of circulatory diseases. Similarly, increases in $\mathrm{NO}$ and $\mathrm{O}_{3}$ are found to augment the number of respiratory diseases, while the number of skin diseases is shown to be risen by an increase in CO concentrations only. Moreover, we find both air pollution and air temperature to be significantly associated with all human health indicators. This work highlights the need for lower air pollution standards for the city of Athens and a wider climate change policy.
\end{abstract}

Keywords: air pollution, air temperature, generalised additive models (GAM), circulatory diseases, respiratory diseases, skin diseases.

Reference to this paper should be made as follows: Mentzakis, E. and Delfino, D., 2010. Effects of Air pollution and Metrological Parameters on Human Health in the city of Athens, Greece. International Journal of Environment and Pollution, 40(1-2), 210-225.

\section{Introduction}

\subsection{Health and air pollution}

The adverse effects of air pollution on human health have become widely acknowledged over the last decades. The London Episode in December of 1952 constituted one of the first realisations of the shortterm effects of air pollution on human health. In that instance, high concentrations of smog and air pollutants along with 'stagnant weather conditions' (Brunekreef and Holgate, 2002) caused 3500-4000 deaths in the first 3 weeks of the episode alone (Bell and Lee Davies, 2001). A number of epidemiological studies have quantified these effects using a variety of analytic/econometric tools, where the causal relationship of mortality/morbidity with air pollution has been found significant for a range of concentration levels (Schwartz and Marcus, 1990; Dockery et al., 1993; Schwartz and Morris, 1995; Katsouyanni et al., 1997; Le Tertre et al., 2002). Furthermore, as some others claim, this

* Corresponding Author. Email: e.mentzakis@abdn.ac.uk 
relationship is not only present for the extreme and the current concentration levels but could hold even for levels lower than the ones generally observed (Katsouyianni et al., 2001; Brunekreef and Holgate, 2002).

\subsection{Health and meteorological parameters}

Moreover, it has been argued that meteorological factors are important determinants of human health. Mortality and morbidity are affected by extreme and moderate weather phenomena, including heat waves and cold spells (Kalkstein, 1991; Braga et al., 2002). Thermal stresses lead not only to direct deaths and illnesses but also to aggravation of cardiovascular and respiratory diseases which, in extreme cases, can even cause death by these causes (Martens, 1996; Haines et al., 2000; Curriero et al., 2002). Additionally, The International Panel on Climate Change (1996) warns about potential adverse effects of climate change, including occurrence of skin cancer and glaucoma, and deaths caused by natural disasters. Evidence suggests that topographic and climate characteristics jointly affect the numbers of deaths and hospital admissions (Smith and Tripak, 1989; Curriero et al., 2002; Patz and Kovats, 2002; Pattenden et al., 2003) making some areas more susceptible to particular weather patterns than others. Although the effects of extreme weather conditions are usually thought to be caused by air temperature and humidity, it is argued that also pressure, precipitation, wind velocity and direction can affect morbidity, especially through interactions with pollutants (Kalkstein, 1993; Jamason et al., 1997; Laschewski and Jendritzky, 2002).

\subsection{Present study}

Using a variety of econometric specifications, the purpose of this study is to quantify the effects of air pollution and meteorological factors on human health and additionally to look for significant differences across the different modelling strategies. To this effect, we employ a generalized additive models framework allowing for non-linearities. In addition, contrary to other studies where daily timeseries are used, we utilize monthly data to display aggregated effects over the period of a month or of adjacent months revealed neither by short nor by long-term studies.

\section{Data}

Athens has a typical Mediterranean climate with mild and rainy winters, relatively long, warm and dry summers and, generally, extended periods of sunshine throughout most of the year. "The topography favours atmospheric inversions and the concentrations of pollutants measured are high even in the presence of relatively limited emissions" (Touloumi et al., 1996).

The Department of Air Quality, operated by the Ministry for the Environment, Physical Planning and Public Works, is the source of the pollution data. The values of the pollutants measured on an hourly basis include carbon monoxide $(\mathrm{CO})$, nitric monoxide $(\mathrm{NO})$, nitric dioxide $\left(\mathrm{NO}_{2}\right)$, sulfur dioxide $\left(\mathrm{SO}_{2}\right)$ and ozone $\left(\mathrm{O}_{3}\right)$; all measured in $\mu \mathrm{g} / \mathrm{m}^{3}$ apart from $\mathrm{CO}$, which is measured in $\mathrm{mg} / \mathrm{m}^{3}$. All the hourly values are initially collapsed to daily average values and then further collapsed to average monthly values. The meteorological measurements are provided by the National Meteorological Service and include average daily figures for average/maximum/minimum air temperature, relative humidity 
and atmospheric pressure. As previously, these daily values are collapsed to average monthly values. Finally, human health data, recorded on a monthly basis, are obtained from hospital records for the area of greater Athens. In particular, morbidity data are proxied by "Patients discharged by main categories of diseases and place of permanent residence". We use three indicators ${ }^{1}$ : "diseases of the circulatory system", "diseases of the respiratory system" 3 and "diseases of the skin and subcutaneous tissue" This study covers the period 01/01/1987 - 31/12/1999. Time series plots and a correlation matrix of the health indicators with the pollution and meteorological variables are presented in Figures 1 to 3 and Table 1.

\subsection{Missing Values}

Despite the density of the data, the imputation of the few missing values is carried out using an imputation by the best-subset regression technique, which creates auxiliary regressions and estimates the values of the missing values. This technique, using linear interpolation or mean of nearby points, is employed and preferred to others as it does not depend strongly on the previous and subsequent patterns of the values. For the variables in question $\left(\mathrm{NO}, \mathrm{NO}_{\mathrm{x}}\right.$ and $\left.\mathrm{NO}_{2}\right)$ the percentage of the imputed values is around $5 \%$. Hence, we identify two datasets, one with filled in missing values and one without. Preliminary analysis is performed comparing the two datasets. Similar results in terms of identification of relationships (positive or negative) with slight variations in quantification are obtained. We, therefore, feel comfortable in using the dataset with imputed values. Both data management and econometric analysis are carried out using Stata/SE 8.2 econometric software.

\section{Methods}

We evaluate the effects of air pollution and weather patterns on human health and test the sensitivity of the results under different model specifications. Three kinds of models are used: Generalised Linear Models (GLM) assuming Gaussian (normal) distribution; GLM assuming Poisson distribution; Generalised Additive Models (GAM) assuming Poisson distribution. As Schwartz et al. (1996) argue, the difference in the results between modelling count data as Poisson or Gaussian is not significant.

A major issue in the literature of epidemiology is the method to deal and control for serial correlation, seasonality and other cyclical patterns. As argued in the APHEA project (Schwartz et al., 1996), there are several ways to address these problems. Parametric approaches with sine and cosine terms (Katsouyianni et al., 1996) and different wavelengths can be used to capture distinct shapes and patterns. As described in the APHEA protocol, the specification would take the following form, $\alpha \sin (2 \pi t / 365)+\beta \cos (2 \pi t / 365)$, where $t=1, \ldots, \mathrm{T}$ is the day of the study (Katsouyianni et al., 1996). However, as in our case the formulation fits the monthly interval series, a slight modification is necessary i.e. the number of days per year is substituted with the number of months per year. We employ terms up to 6th order and select the order that minimises the Akaike's Information Criterion, AIC (Akaike, 1973). Moreover, in order to account for seasonal phenomena we use a dummy variable approach (Wooldridge, 2003) where, instead of using the sinusoidal terms, we fit in each regression a 
series of monthly dummies. This approach is not used to reveal a causal relationship between them but to detect whether during certain months the levels of the diseases are systematically higher or lower. This gives a good approximation of the seasonal and monthly variations and accounts for other seasonal factors excluded from the list of our regressors (e.g. diseases or allergies that escalate during certain months and have a complimentary effect on health). Additionally, a linear and quadratic time trend are introduced in all the models and kept upon their statistical significance and the improvement of the AIC. Subsequently, we test for serial correlation in the residuals. When necessary, autoregressive terms are included in the generalised linear models, as proposed by Schwartz et al. (1996); specifically, the logarithm of weighted moving average terms of the health outcome, $\ln (W M A(Y))$. The employment of all of these techniques corrects all the serial correlation and obtains white noise for all the models' residuals, using correlograms as observation tools, and formal tests such as the Portmanteau (Q) statistic for white noise (Box and Pierce, 1970). It is argued that sometimes this test is not valid for the examination of residuals from linear and non-linear models (Davidson and MacKinnon, 1993). However, plotting the residuals of each model indicates that the normal distribution is followed in every case and, therefore, the outcome of the test is valid.

Furthermore, first and second order lags for of all the explanatory variables are included in all the models apart from the GAM, where only first order lags are fitted. The use of first and/or second order lags provide an extended window of 1 or 2 months, which is more than sufficient since the short and possibly the medium term effects of air pollution and meteorology last usually between 2 to 23 days (Katsouyianni et al., 1997; Laschewski and Jendritzky, 2002; Pattenden et al., 2003).

\subsection{Gaussian Linear Model}

For the Gaussian linear model with a log link function, the expectation of the random variable $Y_{t}$ is

$$
E\left(Y_{t} \mid X_{t}\right)=\exp \left(\beta_{0}+\sum_{i=1}^{n} \beta_{i} X_{i, t}+\ln (W M A(Y))\right)
$$

Here $Y_{t}$ denotes the monthly interval values of the circulatory, respiratory and skin diseases. Here $X_{t}=\left(X_{1, t}, \ldots, X_{i, t}\right)$, where $i=1, \ldots, \mathrm{n}$, denotes all the explanatory variables and $\ln (W M A(Y))$ is the logarithm of the weighted moving average of $Y$.

\subsection{Generalised Linear Model}

For the GLM we use exactly the same specification and procedure as in the Gaussian Linear Model with the difference that here a Poisson distribution is assumed (McCullagh and Nelder, 1989). All the regressors (i.e. air pollutants and meteorological factors) are included and their linear relationship with human health is examined. 


\subsection{Generalised Additive Model}

A GAM is a nonparametric alternative to the GLM. GAMs allow non-linear relationships between the response variable and the control variables (Hastie and Tibshirani, 1990). In a generalised additive Poisson model with a log link function the specified expectation of the $Y_{t}$ is

$$
E\left(Y_{t} \mid X_{t}\right)=\exp \left(\beta_{0}+\sum_{i=1}^{n} g_{i}\left(X_{i, t}\right)\right)
$$

GAM fits a generalized or proportional hazards additive model for the dependent variable as a function of the independent variable by maximising a penalised log likelihood function. Each component of the resulting estimated function of the independent variable is a cubic smoothing spline. The smoothness of each component function is determined by the degrees of freedom $(d f)$ of the respective regressor. Therefore, in our specification every cubic smooth spline used to estimate the non-parametric functions is denoted by $g_{i}$ (Dominici et al., 2002). However, a GAM can be turned into a semi-parametric model including some variables as smooth functions and some others as linear by adjusting the degrees of freedom of the linear independent variables to one. This gives a different specification

$$
E\left(Y_{t} / X_{t}\right)=\exp \left(\beta_{0}+\sum_{r=1}^{p} \beta_{r} X_{r, t}+\sum_{i=1}^{n} g_{i}\left(X_{i, t}\right)\right)
$$

where all the $X_{r, t}$, for $r=1, . ., \mathrm{p}$, are introduced as linear into the model so that we can interpret their effect on the dependent variable. The $X_{i, t}$, where $i=1, . ., \mathrm{n}$, remain cubic smooth functions. The appropriate amount of degrees of freedom is decided using two approaches: the AIC and the difference in deviances. The AIC penalises the amount of degrees of freedom used. The use of too many degrees of freedom can lead to over-specification of the model, resulting in capturing spurious features in the data that are not really a product of the analysed relationship. However, this problem can be detected by looking at the fitted curves and the partial residuals. In the semi-parametric framework we create models where one pollutant, minimum and maximum temperature, and relative humidity are each time introduced as linear, while the remaining variables are included as smooth functions.

The final models and the inclusion of any variable are solely dependent on statistical significance and no relationship is presupposed and held constant. All presented and discussed variables are significant at $5 \%$ confidence level or higher and have passed the necessary formal tests.

\section{Results}

As discussed in the Section 3, graphical examination of the residuals (Figures 4 to 6) reveals no apparent problems with our specified models. Although Figures 4 to 6 are obtained from the GAM for circulatory diseases, the results derived for the rest of diseases and specifications are parallel.

\subsection{Circulatory diseases}

Our results for circulatory diseases (Tables 2 and 3) using the three models are very consistent. In GLM and GAM we find that a $10 \mu \mathrm{g} / \mathrm{m} 3$ increase in SO2 significantly increase circulatory conditions by $0.71 \%$ and $1.27 \%$, respectively. We should note that a positive sign in the coefficient indicates a positive statistical relation between the regressor and the dependent variable, but is translated into a 
negative effect in health terms, since a higher number of diseases indicates worse health. Also NO has a statistically significant impact on circulatory diseases $(0.33 \%$ and $0.53 \%$, respectively) as its first order lagged values $(0.52 \%)$ in the GAM. Furthermore, $\mathrm{O} 3$ is shown to be significant in the additive models with an increase of $0.6 \%$ in circulatory conditions for every $10 \mu \mathrm{g} / \mathrm{m} 3$ increase in O3. The results for meteorological factors are also very consistent amongst the models used. A unit $(1 \mathrm{oC})$ increase in minimum temperature significantly reduces the number of circulatory diseases $(-1.79 \%$ and $-6.91 \%)$, while for every unit $(1 \mathrm{oC})$ increase in maximum and average temperatures the number of circulatory conditions increases by $1.5 \%$ and $2.15 \%$. Similar results are obtained from the GLM models for the second lags of the meteorological parameters. Finally, in the models that used the month dummy variable approach the most harmful months appear to be March and May, while August and September exhibit lower diseases values.

\subsection{Respiratory diseases}

Interesting are also the results for the respiratory diseases (Tables 2 and 3). Nitrogen oxides are generally significant both in the current month as well as their lags. In the GLM models we find that a $10 \mu \mathrm{g} / \mathrm{m}^{3}$ increase in $\mathrm{NO}$ and the second lag of $\mathrm{NO}_{2}$ significantly increase the number of respiratory diseases $\left(0.51 \%\right.$ and $0.6 \% 1.44 \%$ and $1.77 \%$, respectively). For GAM the results reveal that $\mathrm{NO}_{2}$, lagNO $\mathrm{N}_{2}$ and lagNO are damaging, with a $10 \mu \mathrm{g} / \mathrm{m}^{3}$ increase leading to a $0.7 \%, 1.75 \%$ and $0.8 \%$ increase in the numbers of the respiratory diseases, respectively. Similarly, in both specifications a $10 \mu \mathrm{g} / \mathrm{m}^{3}$ increase in $\mathrm{O}_{3}$ is found to significantly increase respiratory diseases by $0.64 \%$ (GAM) and by $1.88 \%$ $(\mathrm{GLM})$. As expected, the additive models indicate that a unit $\left(1^{\circ} \mathrm{C}\right)$ increase in minimum and maximum temperatures significantly reduces the number of respiratory diseases $(-3.72 \%$ and $-6.26 \%, 2.13 \%$ and $4.28 \%$, respectively). However, the effects of average temperature and its lags are insignificant for the GLM models, while minimum temperature, although in just three of the specifications, is shown to have a positive and significant effect $(-0.78 \%$ to $-0.87 \%)$ on respiratory diseases, confirming the consistent influence of minimum temperature on diseases. As in the case of cardiovascular diseases, warmer months (i.e. April, June, July, August, and September) are shown to bear a lower number of respiratory disease occurrences.

\subsection{Skin and subcutaneous tissue diseases}

Finally, skin diseases are weakly affected by air pollution (Tables 2 and 3). For the additive models a significant effect is observed for $\mathrm{CO}$, where a $1 \mathrm{mgr} / \mathrm{m}^{3}$ increase in the pollutant concentration would lead to a $1.98 \%$ increase in the health variable. Similar effect is found for lagNO $(1.09 \%)$ in the GAM, while in the GLM models all the pollution variables are insignificant apart from the second lag of $\mathrm{NO}_{2}$, which appears to be strongly related to skin diseases with a quantified effect of $2.89 \%$ to $3.5 \%$ for every $10 \mu \mathrm{g} / \mathrm{m}^{3}$ increase. However, in all models the results confirm a strong and very consistent influence of temperature. Minimum and maximum temperatures are found (GLM models) to cause a change in the health values $-0.34 \%$ to $-4.92 \%$ and $2.57 \%$ to $4.43 \%$, respectively, for every $1{ }^{\circ} \mathrm{C}$ increase. The same values for all additive models are $-4.92 \%$ to $-5.51 \%$ and $3.33 \%$ to $3.8 \%$, respectively. Again, 
the months that reveal a strong negative influence are April and August, while the ones with a positive one are February, March and December.

In addition, relative humidity, when added to the models as linear, is significant for almost all cases, revealing always a $0.28 \%$ to $0.73 \%$ rise in the health values for every percentage increase.

\section{Discussion}

Our results confirm some of the outcomes stated in the literature and the use of monthly intervals does not affect the quality of these results. Furthermore, the employment of different model specifications and the different methods to account for seasonality do not have any explicit significant effect on our conclusions leading to quite comparable results among the various methods. Hence, the recommendation to use one approach rather than the other is not appropriate and the choice should be based mainly on the type of data and the problems that are analysed, like seasonality and other cyclical events.

In a previous study in Athens (Touloumi et al., 1996), $\mathrm{SO}_{2}$ is positively correlated with health showing a $3 \%$ to $8 \%$ increase in total number of daily deaths for every additional $100 \mu \mathrm{g} / \mathrm{m}^{3}$ of $\mathrm{SO}_{2}$, which is very close to our estimates of $0.71 \%$ to $1.27 \%$ for every $10 \mu \mathrm{g} / \mathrm{m}^{3}$. Parallel results are presented for cities in Southern Europe by Katsouyianni (1995), who finds associations between $\mathrm{SO}_{2}$ and cardiac complications/mortality. Similarly, amongst the studies that use hospital admission records, Schwartz and Morris (1995) report a relative risk of 1.018 in heart diseases for every 18ppb (parts per billion) increase in $\mathrm{SO}_{2}$, while the increase that Burnet et al. (1995) report is $2.8 \%$ for every $13 \mu \mathrm{g} / \mathrm{m}^{3}$. Significant are also the effects of pollutants such as $\mathrm{NO}_{2}$ and NO. In a study in metropolitan Los Angeles (Linn et al., 2000) an increase of 14\% in hospital admissions for cardiovascular diseases is reported for every 10pphm (parts per hundred millions) increase in $\mathrm{NO}_{2}$ levels. An increase in mortality of $3.1 \%$ is also concluded for each interquartile range increase in $\mathrm{NO}_{2}$, in a study in Korea (Hong et al., 2002), while the cardiovascular deaths related to air pollution rise by $1 \%$ for every $10 \mu \mathrm{g} / \mathrm{m}^{3}$ increase in $\mathrm{NO}_{2}$ levels, for seven cities of Spain (Saez et al., 2002). In another study, Cho et al. (2000) conclude that, for respiratory admissions, the relative risk in relation to $\mathrm{NO}_{2}$ is 1.47 (95\% C.I.: 1.03-2.10). Similarly, Schwartz (2004) argues that NO effects on respiratory problems are quite apparent, especially on children, while Braat et al. (2002) link NO to the aggravation of respiratory diseases and allergies, although the significance level of the pollutant could not allow for generalisations. These results are very close to the ones obtained from our models where $\mathrm{NO}_{2}$ and its lags are highly significant with effects ranging from $0.7 \%$ to $1.77 \%$ for every 10 unit increase. Overall, although deterioration in human health by NO is not very common, the harmful effects of nitric oxides are widely acknowledged by the literature.

In our study $\mathrm{O}_{3}$ results to be irrelevant for circulatory diseases, a conclusion reached also by Anderson et al. (1996). The impact of $\mathrm{O}_{3}$ in respiratory diseases is similar to that obtained by other studies (Brunekreef and Holgate, 2002; Desqueyroux et al., 2002; Sunyer et al., 2002). However, deaths from respiratory diseases attributed to exposure to $\mathrm{O}_{3}$ are found to be also significant (Anderson et al., 1996; Goldberg et al., 2001; Hong et al., 2002). Desqueyroux et al. (2002) report that a $10 \mu \mathrm{gr} / \mathrm{m}^{3}$ increase is associated with an increase in the relative risk $(\mathrm{OR}=1.20,95 \% \mathrm{CI})$ of asthma attack, while a 
study in Barcelona (Sunyer et al., 2002) concludes that $\mathrm{O}_{3}$ increases the risk of dying in asthmatic patients $(\mathrm{OR}=1.90,95 \% \mathrm{CI})$. Similarly, Katsouyianni (2003) reports results from one study where a $20 \mu \mathrm{gr} / \mathrm{m}^{3}$ increase in $\mathrm{O}_{3}$ is associated with $0.5 \%$ increase in respiratory mortality and from another study where a $2.9 \%$ increase is the result of raising the concentration of $\mathrm{O}_{3}$ by $50 \mu \mathrm{g} / \mathrm{m}^{3}$. After taking into account the scale that each study uses, we can observe that our results do not differ from what is previously reported, since our estimates predict a $0.64 \%$ to $1.88 \%$ rise for every $10 \mu \mathrm{g} / \mathrm{m}^{3}$.

The relation of air pollution and skin diseases is rarely a subject of study in the literature (Mar and Marks, 1999; Polosa, 1999; Forster and Kuehr, 2000). As we observed, the most consistent effects for skin diseases come from temperature. Yet, temperature is inseparably connected to sun and sunlight, as is ground-level ozone. Likewise, Brunekreef and Holgate (2002) confirm "high ozone concentrations during warm and sunny weather" (p.1233). Thus, it is possible that the harmful effects on skin diseases, revealed through $\mathrm{O}_{3}$ and temperatures, are a complementary effect. It is well know that sunlight and radiation are amongst the main causal factors for skin diseases. Unfortunately "sunshine duration" was not available in our dataset. We could argue, however, that the relationship of skin diseases with the harmful side of sunlight is revealed through the significance of temperature.

Finally, our results for air temperature also confirm previous findings, with increases in average and maximum air temperatures leading to increased number of the health indicators, which given their very high positive correlation (Table 4 ) is to be expected. On the contrary, the negative sign of minimum temperature indicates that increase in minimum temperature would result in better health outcomes, confirming that alleviation of extreme temperatures is beneficial to the human organism especially in the high-risk populations. As in Patz and Kovats (2002) and Curriero et al. (2002), populations in warmer/temperate climates tend to be more sensitive to low temperatures, while population of colder climates are more vulnerable to heat.

Similarly, Smith and Tirpak (1989) argue that heat affects mortality to a greater extent in cities with temperate climate, while cities with warmer climates, and therefore smaller variance in their summer temperatures, tend to be more protected, irrelevantly of the extent to which the temperature might rise. In another study comparing London and Sofia (Pattenden et al, 2003), the impact of heat is greater for Sofia while cold is for London; a possible explanation for this could be the acclimatisation of the population and their distinct habits and behaviours. Similarly, McGeehin and Mirabelli (2001) find that north-eastern and mid-western U.S. cities are likely to experience higher number of admissions in response to changes in the summer temperatures.

In a very comparable framework we support the dummy variable approach to correct for seasonality. Generally, higher temperatures and better weather conditions are observed during warm months leading to less illness incidents. Similarly, the effect of better lifestyle during summer months involves less stress, more exercise (probably swimming) and a more relaxed pace. In the future this association should be tested rigorously in order to make sure that the use of weather variables is not capturing spurious effects through differences in lifestyles or possible correlations with diseases outbreaks, rather than the true harmful consequences of meteorological events. 


\section{Conclusion}

By sequence of testing, our results indicate that an exacerbation in pollution levels of $\mathrm{SO}_{2}$ significantly increase the number of circulatory diseases. Similarly, increases in $\mathrm{NO}$ and $\mathrm{O}_{3}$ are found to augment the number of respiratory diseases, while the number of skin diseases is shown to be risen by an increase in $\mathrm{CO}$ concentrations only. We could argue that further lowering of the pollution levels would be beneficiary for the population health in the city of Athens.

It is, also, apparent that air temperature is an important determinant of health. We find statistically significant evidence for a causal relationship of air pollution and air temperature with all human health indicators. As a corollary, the fast growing effects of climate change and its effect on temperature could prove to be one of the main influences on health in the future.

Data limitations (monthly data for health indicators) do not allow testing whether in-month variation of pollution and temperature has any influences on health, while the combined effects of pollution and temperature on health were also ignored. Future research should concentrate in testing the existence of multiplicative effects or of cancelling out. Finally, we do not test the sensitivity of our results to the hourly/daily to monthly averages transformation method and whether the use of accumulated during the month quantities with or without threshold is be more informative than the averaged ones. This should be explored in the future.

\section{Acknowledgements}

We would like to thank three anonymous reviewers for their helpful comments and suggestions. We also thank Professor Matt Sutton for his helpful comments on the analytical part. Thanks are finally due to the Department of Air Quality, Ministry for the Environment, Physical Planning and Public Works, to the Hellenic National Meteorological Service and to the National Statistical Service of Greece for the provision of air pollution, meteorological and morbidity data, respectively.

\section{References}

Akaike, H., 1973. Information theory and an extension of the maximum likelihood principle. In: B.N. Petrov and F. Csaki (eds), 2nd International Symposium of Information Theory, Akademia Kidao, Budapest, 267-281.

Anderson, R.H., A. Ponce de Leon, J.M. Bland, J.S. Bower and D.P. Strachan, 1996. Air pollution and daily mortality in London: 1987-92. British Medical Journal, 312, 665-669.

Bell, M.L. and D.L. Davies, 2001. Reassessment of the lethal London fog of 1952: Novel indicators of acute and chronic consequences of acute exposure to air pollution. Environmental Health Perspectives Supplements, 109, S3: 389-394.

Box, G., and D. Pierce, 1970. Distribution of Residual Autocorrelations in Autoregressive Moving Average Time Series Models. Journal of the American Statistical Association, 65, 1509-1526.

Braga, A.L.F., A. Zanobetti and J. Schwartz, 2002. The effect of weather on respiratory and cardiovascular deaths on 12 U.S. Cities. Environmental Health Perspectives, 110, 859-863.

Braat, J. P. M., P. G. Mulder, H. J. Duivenvoorden, R. Gerth Van Wijk, E. Rijntjes and W. J. Fokkens, 2002, Pollutional and meteorological factors are closely related to complaints of non-allergic, non-infectious perennial rhinitis patients: a time series model. Clinical \& Experimental Allergy, 32, 690-697.

Brunekreef, B. and S.T. Holgate, 2002. Air pollution and health. The Lancet, 360, 1233-1242.

Cho,B., J. Choi, and Y.T. Yum, 2000. Air Pollution and Hospital Admissions for Respiratory Disease in Certain Areas of Korea. Journal of Occupational Health, 42 (2), 185-191.

Curriero, F.C., K.S. Heiner, J.M. Samet, S.L. Zeger, L. Strug and J.A. Patz, 2002. Temperature and Mortality in 11 Cities of 
the Eastern United States. American Journal of Epidemiology, 155, 80-87.

Davidson R. and J.G. MacKinnon, 1993. Estimation and Inference in Econometrics. New York: Oxford University Press.

Desqueyroux, H., J.C. Pujet, M. Prosper, F. Squinazi and L. Momas, 2002. Short-Term Effects of Low-Level Air Pollution on Respiratory Health of Adults Suffering from Moderate to Severe Asthma. Environmental Research, 89 (1), 29-37(9).

Dockery, D. W., C.A. Pope III, X. Xu, J.D. Spengler, J.H. Ware, M.E. Fay, B.B.G. Ferris and F.E. Speizer, 1993. An Association between Air Pollution and Mortality in Six U.S. Cities. New England Journal of Medicine, 329 (24), $1753-$ 1759.

Dominici, F., A. McDermott, S.L. Zeger and J.M. Samet, 2002. On the use of generalized additive models in the time-series studies of air pollution and health. American journal of Epidemiology, 156, 193-203.

Forster, J and J. Kuehr, 2000. The role of ozone. Pediatric Allergy and Immunology, Suppl. 13, 23-25.

Goldberg, M.S., R.T. Burnett, J. Brook, J.C. Bailar, M.F. Valois and R. Vincent, 2001. Associations between daily causespecific mortality and concentrations of ground-level ozone in Montreal, Quebec. American Journal of Epidemiology, 154 (9), 817-826.

Haines, A., A.J. McMichael, P.R. Epstein, 2000. Environment and Health: 2.Global climate change and health. Journal of Canadian Medical Association, 163 (6), 729-734.

Hastie, T.J. and R.J. Tibshirani, 1990. Generalized additive models. New York: Chapman and Hall, Inc.

Hong Y.C., J.T. Lee, H. Kim, E.H. Ha, J. Schwartz, D.C. Christiani, 2002. Effects of air pollutants on acute stroke mortality. Environmental Health Perspectives, 110 (2), 187-91.

International Panel on Climate Change, 1996. Technical paper 1 and 2. Technologies, policies and measures. Available from: http://www.ipcc.ch/pub/IPCCTP.I(E).pdf and http://www.ipcc.ch/pub/IPCCTP.II(E).pdf [Accessed 25 June 2004].

Jamason, P.F., L.S. Kalkstein and P.J. Gergen, 1997. A Synoptic Evaluation of Asthma Hospital Admissions in New York City. American Journal of Respiratory and Critical Care Medicine, 156. 1781-1788.

Kalkstein, L.S., 1991. A New Approach to Evaluate the Impact of Climate on Human Mortality. Environmental Health Perspectives, 96, 145-150.

Kalkstein, L.S., 1993. Direct impacts in cities. The Lancet, 342,1397-1399.

Katsouyanni, K., 2003. Ambient air pollution and health. British Medical Bulletin, 68, 143-156.

Katsouyanni, K., G. Touloumi, C. Spix, J. Schwartz, F. Balducci, S. Medina, G. Rossi, B. Wojtyniak, J. Sunyer, L. Bacharova, P.J. Schouten, A. Ponka, A. and H.R. Anderson, 1997. Short term effects of ambient sulphur dioxide and particulate matter on mortality in 12 European cities: results from time series data from the APHEA project. British Medical Journal, 314 , 1658-1663.

Katsouyanni, K., J. Schwartz, C. Spix, G. Touloumi, D. Zmirou, A. Zanobetti, B, Wojtyniak, J.M Vonk, A. Tobias, A. Ponka, S. Medina, L. Bacharova, H.R. Anderson, 1996. Short-term effects of air pollution on health: a European approach using epidemiologic time-series data: the APHEA protocol. Journal of Epidemiology and Community Health, 50, S12-S18.

Katsouyianni, K., 1995. Health effects of air pollution in Southern Europe: Are there interacting factors?. Environmental health Perspectives, 103, S2: 23-27.

Katsouyianni, K., G. Touloumi, E. Samoli, A. Gryparis, A. Le Terte, Y. Monopolis, G. Rossi, D. Zmirou, F. Ballester, A. Boumghar, H.R. Anderson, B. Wojtyniak, A. Padly, R. Braunstein, J. Pekkanen, C. Schindler and J. Schwartz, 2001. Comfounding and effect modification in the short-term effects of ambient particles on total mortality: results from 29 European cities within the APHEA 2 project. Epidemiology, 12, 521-531.

Laschewski, G. and G. Jendritzky, 2002. Effects of the thermal environment on human health: an investigation of 30 years of daily mortality data from SW Germany. Climate Research, 21, 91-103.

Le Tertre, A., S. Medina, E. Samoli, B. Forsberg, P. Michelozzi, A. Boumghar, J.M. Vonk, A. Bellini, R. Atkinson, G. Ayres, J. Sunyer, J. Schwartz and K. Katsouyanni, 2002. Short-term effects of particulate air pollution on cardiovascular diseases in eight European cities. Journal of Epidemiology and Community Health, 56, 773-779.

Linn, W. S., Y. Szlachcic, H. Gong Jr., L. Patrick, P.L. Kinney and K.T. Berhane, 2000. Air Pollution and Daily Hospital Admissions in Metropolitan Los Angeles. Environmental Health Perspectives, 108 (5), 427-434.

Mar, A. and R. Marks, 1999. The descriptive epidemiology of atopic dermatitis in the community. Australasian Journal of Dermatology, 40, 73-78.

Martens, W.J.M., 1996. Global atmospheric change and human health: an integrated modelling approach. Climate Research, 6, 
107-112

McCullagh, P. and J.A. Nelder, 1989. Generalized linear models, Chapman and Hall, Inc, London, UK.

McGeehin, M.A. and M. Mirabelli, 2001. The Potential Impacts of Climate Variability and Change on Temperature-Related Morbidity and Mortality in the United States. Environmental Health Perspectives, 109, 185-189.

Pattenden, S., B. Nikiforov and B.G. Armstrong, 2003. Mortality and temperature in Sofia and London. Journal of Epidemiology and Community Health, 57, 628-633.

Patz, J.A. and R.S. Kovats, 2002. Hotspots in climate change and human health. British Medical Journal, 325, 1094-1098.

Polosa, R., 1999: Prevalence of atopy and urban air pollution: dirty business. Clinical and Experimental Allergy, 29, 14391441.

Saez, M., F. Ballester, M.A. Barceló et al., 2002. A Combined Analysis of the Short-Term Effects of Photochemical Air Pollutants on Mortality within the EMECAM Project. Environmental Health Perspectives, 110 (3), 221-228.

Schwartz, J., 2004. Air Pollution and Children's Health. Pediatrics, 113, 4, 1037-1043.

Schwartz, J. and A. Marcus, 1990. Mortality and Air Pollution in London: Time Series Analysis. American Journal of Epidemiology, 131, 185-193.

Schwartz, J. and B. Morris, 1995. Air Pollution and Hospital Admissions for Cardiovascular Disease in Detroit, Michigan. American Journal of Epidemiology, 142, 23-35.

Schwartz, J., C. Spix, G. Touloumi, L. Bacharova, T. Barumamdzadeh, A. le Tertre, T. Piekarksi, A. Ponce de Leon, A. Ponka, G. Rossi, M. Saez and J.P. Schouten, 1996. Methodological issues in studies of air pollution and daily counts of deaths or hospital admissions. Journal of Epidemiology and Community Health, 50, Suppl 1, S3-11.

Smith, J. and D.A Tripak (eds), 1989. The potential effects of global climate change on the United States: report to Congress. Washington, DC.: Environmental Protection Agency.

Sunyer, J., X. Basagana, J. Belmonte and J.M. Anto, 2002. Effect of nitrogen dioxide and ozone on the risk of dying in patients with severe asthma. Thorax, 57, 687-693

Touloumi, G, E. Samoli, K. Katsouyanni, 1996. Daily mortality and "winter type" air pollution in Athens, Greece-a time series analysis within the APHEA project. Journal of Epidemiology and Community Health, 50, S47-S51.

Wooldridge, J.M., 2003. Introductory Econometrics: a modern approach. 2nd edition. US: Thomson South-Western.

\section{Notes}

${ }^{1}$ Categorised according to the International Classification of Diseases, $9^{\text {th }}$ revision (ICD-9)

2 ICD-9: 390-398, 401-405, 410-417, 420-438, 440-448 and 451-459.

3 ICD-9: 460-466, 470-478, 480-487, 490-496, 500-508 and 510-519.

${ }^{4}$ ICD-9: 680-686, 690-698 and 700-709. 
Table 1. Correlation of health indicators with the rest of the regressor ${ }^{\mathrm{a}}$.

\begin{tabular}{cccc}
\hline & $\begin{array}{c}\text { Circulatory } \\
\text { Diseases }\end{array}$ & Respiratory Diseases & Skin Diseases \\
\hline $\mathrm{CO}$ & -0.3387 & 0.1034 & -0.1184 \\
$\mathrm{NO}$ & -0.1565 & 0.2638 & -0.1437 \\
$\mathrm{NO}_{2}$ & -0.4984 & 0.0011 & -0.1174 \\
$\mathrm{SO}_{2}$ & -0.2461 & 0.1914 & -0.2223 \\
$\mathrm{O}_{3}$ & -0.0641 & -0.4360 & 0.0294 \\
\hline Average Temperature & -0.3948 & -0.6420 & 0.0075 \\
Minimum Temperature & -0.4227 & -0.6785 & -0.0099 \\
Maximum Temperature & -0.3961 & -0.6289 & 0.0152 \\
Humidity & 0.3706 & 0.5364 & 0.0367 \\
Pressure & 0.2162 & 0.3650 & -0.0610 \\
\hline
\end{tabular}

${ }^{a}$ The correlation coefficient does not depend on the units of measurement and a coefficient of 0.10 indicates a $10 \%$ positive correlation between the two variables. 
Table 2. Results from the Gaussian and the Poisson distributed GLMs*

\begin{tabular}{|c|c|c|c|}
\hline & Circulatory diseases & Respiratory diseases & Skin diseases \\
\hline $\mathrm{NO}$ & $0.33 \%$ to $0.53 \%$ & $0.51 \%$ to $0.6 \%$ & \\
\hline $\mathrm{SO} 2$ & $\begin{array}{c}1 \% \text { to } 1.27 \%(\mathrm{GLM} \\
\mathrm{AR})\end{array}$ & & \\
\hline O3 & & $1.88 \%(\mathrm{GLM} \sin \mathrm{AR})$ & \\
\hline Average Temperature & $1.5 \%$ to $4.03 \%$ & & \\
\hline $\begin{array}{l}\text { Minimum } \\
\text { Temperature }\end{array}$ & $-1.79 \%$ to $-4.9 \%$ & $-0.78 \%$ to $0.87 \%$ & $-3.34 \%$ to $-4.92 \%$ \\
\hline $\begin{array}{l}\text { Maximum } \\
\text { Temperature }\end{array}$ & & & $2.57 \%$ to $4.43 \%$ \\
\hline Humidity & $0.28 \%$ to $0.36 \%$ & & $0.5 \%$ to $0.73 \%$ \\
\hline lagNO & & & $0.51 \%($ REG $\sin )$ \\
\hline $\operatorname{lagNO} 2$ & $0.42 \%$ to $1.6 \%(\mathrm{AR})$ & & \\
\hline $\begin{array}{l}\text { lag Average } \\
\text { Temperature }\end{array}$ & $\begin{array}{c}-0.52 \% \text { to }-2.56 \% \\
\text { (AR) }\end{array}$ & & \\
\hline lag2NO2 & & $1.44 \%$ to $1.77 \%$ & $2.89 \%$ to $3.5 \%$ \\
\hline $\begin{array}{l}\text { lag2Average } \\
\text { Temperature }\end{array}$ & $5.51 \%$ to $7.12 \%$ & $-0.79 \%$ to $-4.6 \%$ & \\
\hline $\begin{array}{l}\text { lag2Minimum } \\
\text { Temperature }\end{array}$ & $-2.36 \%$ to $3.24 \%$ & & \\
\hline $\begin{array}{l}\text { lag2Maximum } \\
\text { Temperature }\end{array}$ & $-2.95 \%$ to $-4.18 \%$ & $3 \%$ to $4.83 \%$ & \\
\hline $\begin{array}{l}\text { Positive Relation } \\
\text { months }\end{array}$ & May/March & Oct/Mar/Feb & Feb/Mar/Dec \\
\hline $\begin{array}{l}\text { Negative Relation } \\
\text { months }\end{array}$ & August/ September & Jun/Jul/Aug/Sep & August \\
\hline
\end{tabular}

* The acronyms indicate particular results originating in specific models which have the following connotation: a) GLM AR denotes an autoregressive GLM model, b) GLM sin AR denotes an autoregressive model with sinusoidal terms and c) REG sin denotes a normally distributed GLM with sinusoidal terms. 
Table 3. Results from the Poisson distributed GAMs.

\begin{tabular}{|c|c|c|c|}
\hline & Circulatory diseases & Respiratory diseases & Skin diseases \\
\hline $\mathrm{CO}^{\prime}$ & & & $1.98 \%$ \\
\hline NO2 & & $0.7 \%$ & \\
\hline $\mathrm{SO} 2$ & $0.71 \%$ & & \\
\hline $\mathrm{O} 3$ & & $0.64 \%$ & \\
\hline $\begin{array}{l}\text { Minimum } \\
\text { Temperature }\end{array}$ & $-5.05 \%$ to $-6.91 \%$ & $-3.72 \%$ to $-6.26 \%$ & $-4.29 \%$ to $5.51 \%$ \\
\hline $\begin{array}{l}\text { Maximum } \\
\text { Temperature }\end{array}$ & $-1 \%$ to $2.15 \%$ & $2.13 \%$ to $4.28 \%$ & $3.33 \%$ to $3.8 \%$ \\
\hline Humidity & $0.36 \%$ to $0.61 \%$ & $0.2 \%$ to $0.71 \%$ & $0.38 \%$ to $0.59 \%$ \\
\hline lagNO & $0.52 \%$ & $0.8 \%$ & \\
\hline $\operatorname{lagNO} 2$ & & $1.75 \%$ & $1.09 \%$ \\
\hline lagO3 & $0.6 \%$ & & \\
\hline $\begin{array}{l}\text { lag Minimum } \\
\text { Temperature }\end{array}$ & & $1.55 \%$ to $4.61 \%$ & $2.31 \%$ to $3.54 \%$ \\
\hline $\begin{array}{l}\text { lag Maximum } \\
\text { Temperature }\end{array}$ & $-1.2 \%$ to $4.95 \%$ & $1.04 \%$ to $3.21 \%$ & $5.9 \% * *$ \\
\hline $\begin{array}{l}\text { Positive Relation } \\
\text { months }\end{array}$ & All months & & \\
\hline $\begin{array}{l}\text { Negative Relation } \\
\text { months }\end{array}$ & & Apr /Aug & Apr/Aug \\
\hline
\end{tabular}

** This result was observed in the GAM model, where CO and its lagged form where the linear pollution variables of the model.

Table 4. Statistics of Average and Maximum Temperature (measured in ${ }^{\circ} \mathrm{C}$ )

\begin{tabular}{llll|c}
\hline Variable & Mean & Min & Max & \multicolumn{1}{c}{ Pairwise Correlation } \\
\hline Average Temperature & 17.83 & 6.04 & 30.52 & 0.9978 \\
Maximum Temperature & 22.70 & 9.28 & 36.16 & \\
\hline
\end{tabular}



Figure 1 Monthly time series of health indicators, January 1987-December 1999

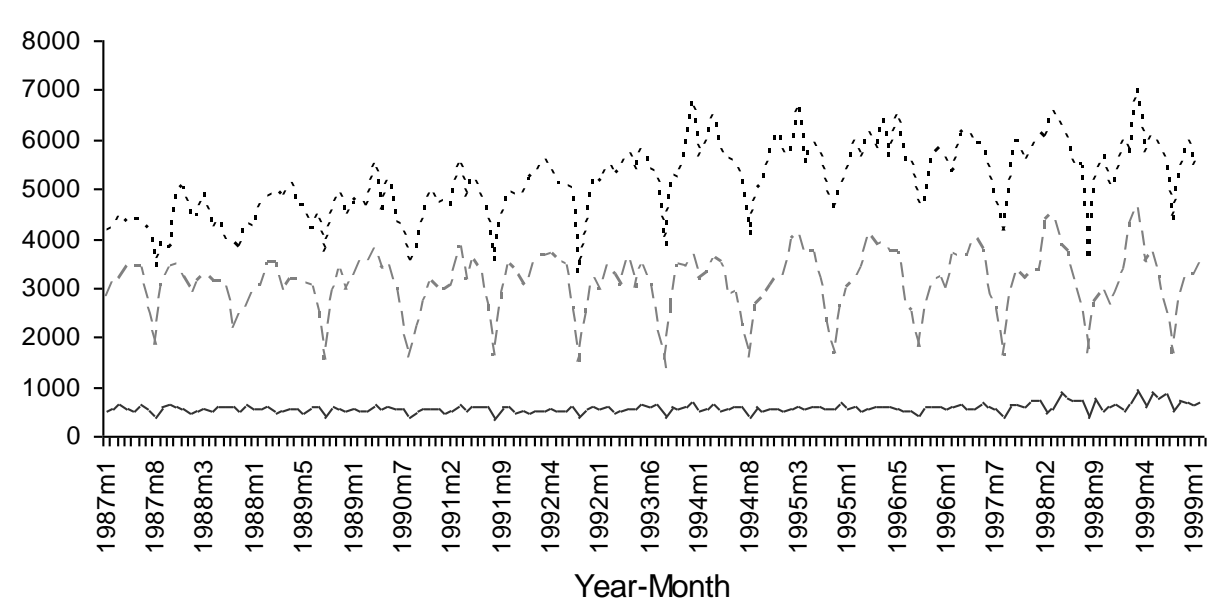

\section{…... Circulatory diseases --- - Respiratory Diseases _- Skin Diseases}

Figure 2 Monthly time series of air pollutants, January 1987-December 1999

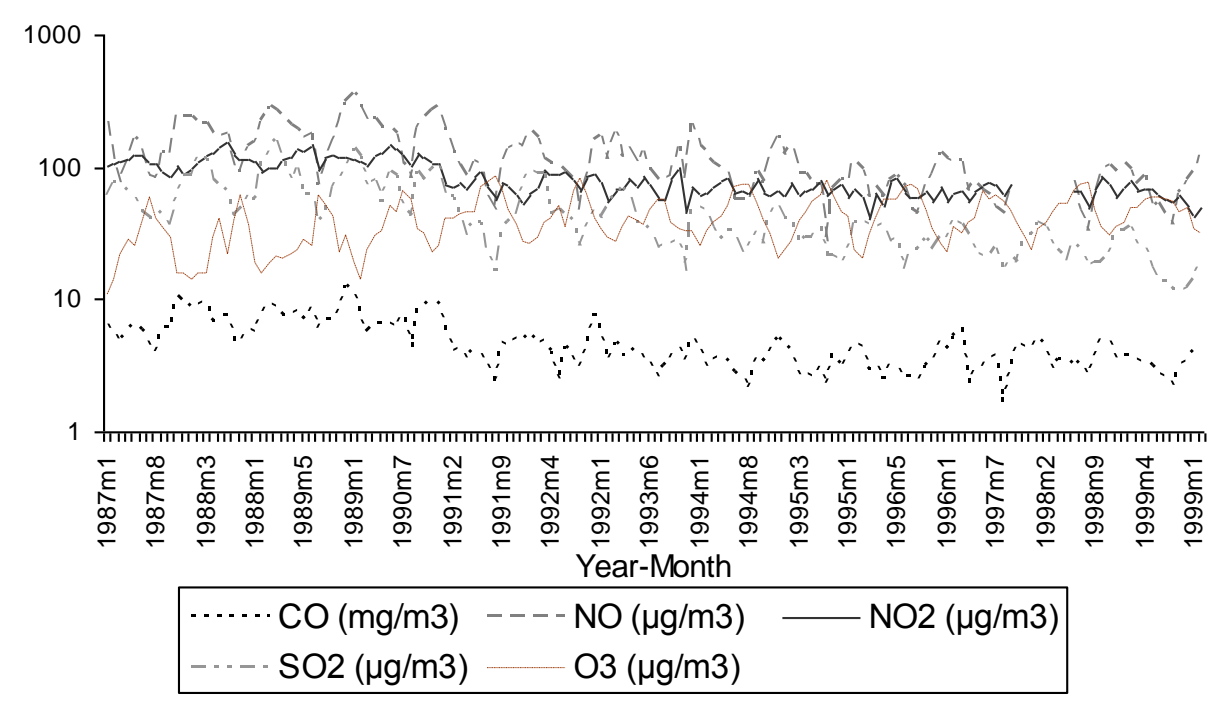


Figure 3 Monthly time series of meteorological parameters, January 1987-December 1999



Year-Month

\begin{tabular}{|c|c|}
\hline Avg. Temperature ( $\left.{ }^{\circ} \mathrm{C}\right)$ & ---- Max. Temperature $\left({ }^{\circ} \mathrm{C}\right)$ \\
\hline _ Min.Temperature $\left({ }^{\circ} \mathrm{C}\right)$ & -..- Humidity (\%) \\
\hline
\end{tabular}

Figure 4 Autocorrelations for Circulatory Diseases Residuals.

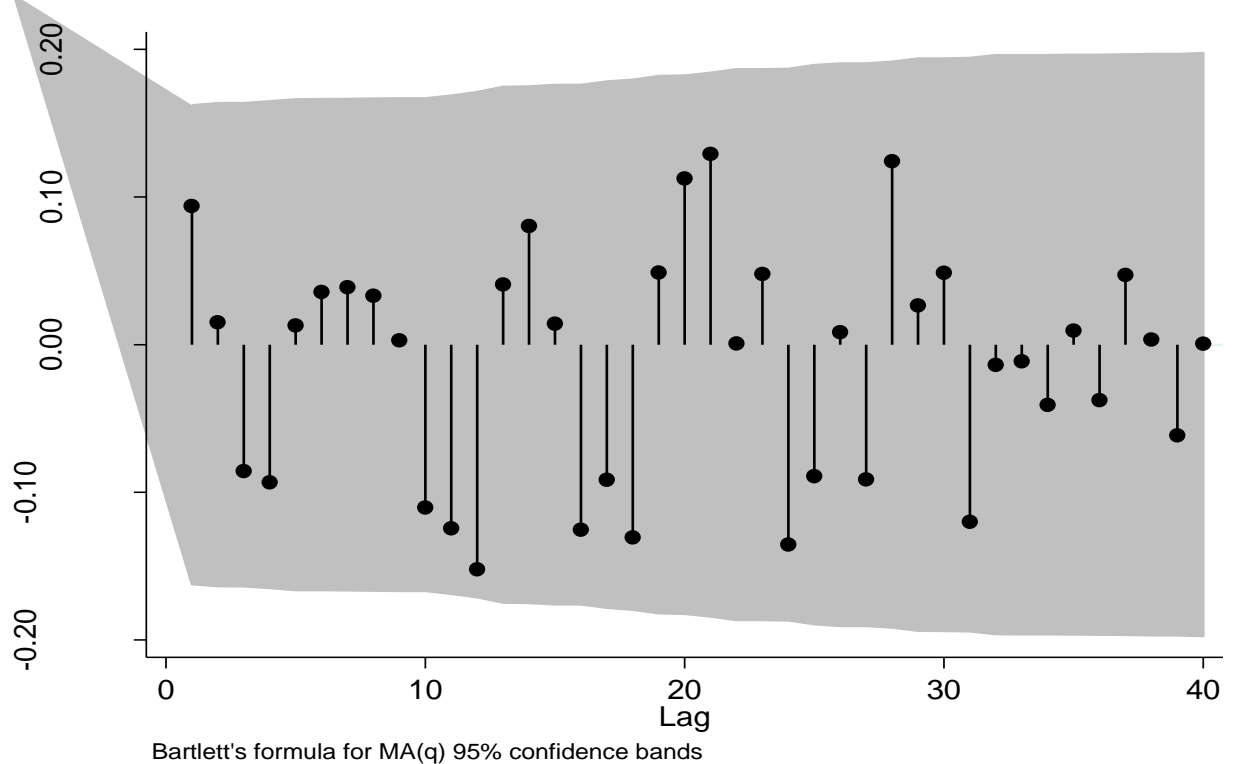


Figure 5 Partial Autocorrelations for Circulatory Diseases Residuals.



Figure 6 Distribution of Circulatory Residuals against the normal distribution.

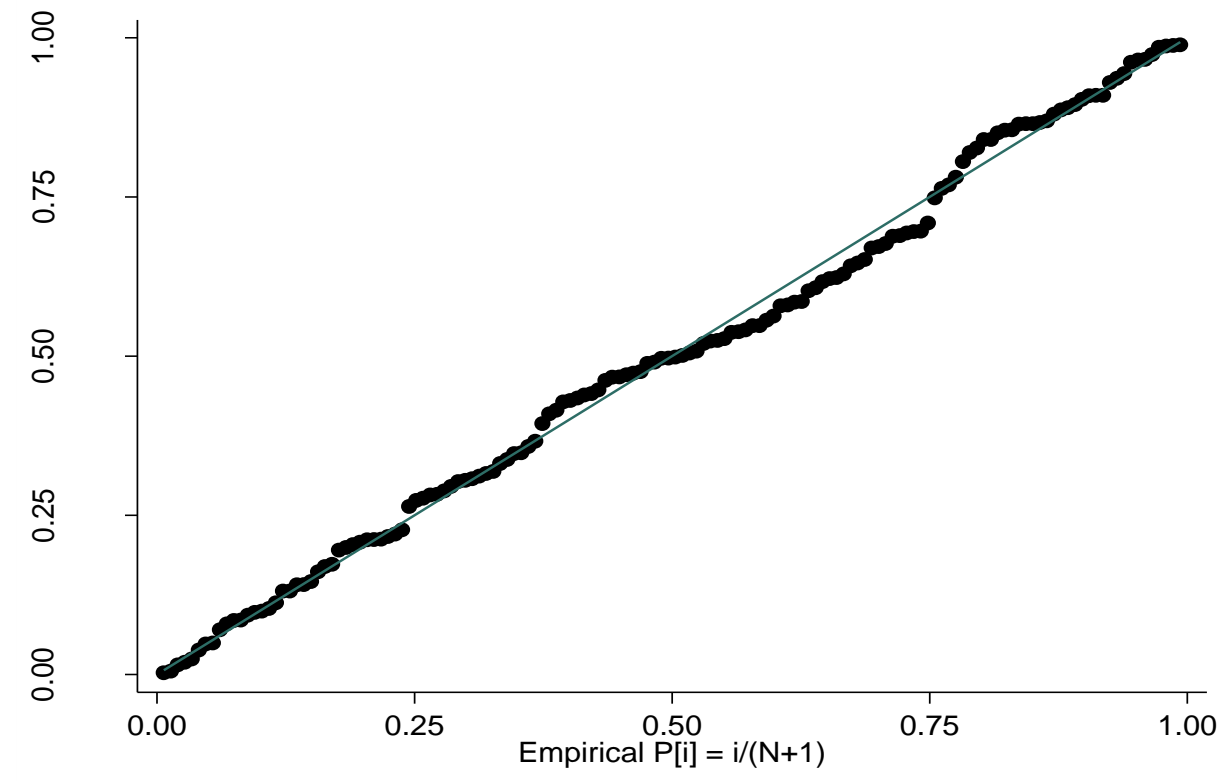

